\title{
Management of Bisphosphonate-related Osteonecrosis of the Jaw in an Elderly Lebanese Female
}

\author{
Jihad Abdallah \\ Clinical Professor, Department of Oral and Maxillofacial Surgery, Faculty of Dentistry, Beirut Arab University (BAU), Lebanon
}

Correspondence: Jihad Abdallah, Beirut Implant and Esthetic Dentistry Center (BIDC), Cairo Street Zakka Building, 2nd Floor Hamra, Beirut, Lebanon, Phone: +9613334004, e-mail: beirutidc@hotmail.com

\section{ABSTRACT}

The use of bisphosphonates (BP) in the treatment of osteopenia and osteoporosis, other than in cancer patients, has been described now for several years. Medical and dental literature in the last decade described the emergence of a new disease, bisphosphonate related osteonecrosis of the jaw (BRONJ), after dental surgical intervention in patients on bisphosphonates. The pathogenesis and complete mechanisms of BRONJ are still unclear, and there is still no all-inclusive understanding of the stages of BRONJ. In this paper, we will describe the treatment of a Lebanese elderly female who had BRONJ after surgical dental treatment. This specific case did not follow the stages set by AAOMS in 2009, and calls for a better understanding of BRONJ and its mechanisms. Better patient education and documentation must be undertaken to decrease the risk of developing BRONJ due to dental procedure.

Keywords: Bisphosphonates, Osteoporosis, Osteonecrosis, BRONJ.

\section{INTRODUCTION}

In the 1960s, bisphosphonates (BP) were first used as a possible treatment of Paget's disease, tumor-induced hypercalcemia and bone metastases. ${ }^{1}$ In the 1990s, BPs became the standard treatment for osteoporosis. ${ }^{1}$ In 2003, Robert E Marx published the discovery of an extremely therapy-resistant osteonecrosis of the jaws (ONJ). ${ }^{2}$ Patients who suffered with this kind of ONJ had all received bisphosphonate treatment for metastatic bone disease or osteoporosis. ${ }^{2}$ Marx, thus, concluded that there is a correlation between BP therapy and this acute osteonecrosis of the jaws. ${ }^{2}$ This was not the first time that this condition was reported in medical literature, however, the "Phossy Jaw" was first described in the British medical journal in 1899 (Fig. 1). ${ }^{3}$ Phosphorus matches were first sold in the UK in 1827, creating a new industry of cheap lights, but at high human cost. Breathing in phosphorus vapor led to the industrial disease phossy jaw, which slowly ate away the jaw bone. ${ }^{4,5}$ This condition particularly afflicted the girls who made phosphorus matches. ${ }^{3}$ Finally, the year 1910 saw the birth of legislation prohibiting the use of white phosphorus in British match factories and instructing factory owners to use the safer yet more expensive red phosphorous instead. ${ }^{4,5}$

\section{REVIEW OF THE LITERATURE}

BRONJ has only been discussed in less than a decade's worth of literature. Starting with Robert E Marx's publication in 2003, researchers began to expand this new

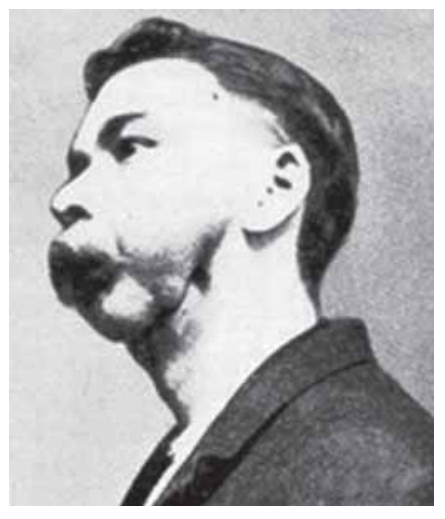

Fig. 1: An English factory worker experiencing the phossy jaw condition. Exposed bone can be observed at the chin ${ }^{3}$

field of study, and many publications on the topic surfaced worldwide in the following years. The only textbook on BRONJ was written by Marx (2006): Oral and Intravenous Bisphosphonate-induced Osteonecrosis of the Jaws. ${ }^{6}$ In the same year, the American Dental Association (ADA) addressed this condition in its recommendations, updated in 2008, ${ }^{7}$ followed shortly by the American Academy of Oral Maxillofacial Surgeons (AAOMS) in their 2007 position paper, ${ }^{8}$ later updated in 2009. ${ }^{9}$ In 2010 , the Allied Japanese Task Force Committee summarized and compiled all of the research done on BRONJ, presenting a position paper that did not use direct clinical evidence but focused on combining all the literature written so far on the subject so that it can be used in future research. ${ }^{10}$ In March 2010, an extensive five-year prospective clinical study was 
presented at the American Association for Dental Research (AADR) conference studying a significant number of cases and collecting valuable statistics. ${ }^{11}$ However, the fact stands that all of the literature on BRONJ is less than a decade old, and BRONJ remains a condition of unclear pathogenesis, prevention and treatment. ${ }^{10}$

\section{Bisphosphonates and Mode of Action}

Bisphosphonate drugs are based on variations of the bisphosphonate molecule. The strong P-C-P backbone (Figs 2A and B) makes bisphosphonates resistant to hydrolytic breakdown, thus giving it a long half-life. The $\mathrm{R}_{1}$ group is the site that binds to hydroxylapatite in bone while the $\mathrm{R}_{2}$ chain determines potency of the drug. Nitrogencontaining side chains and rings are most potent. ${ }^{6}$

Bisphosphonates bind to bone through the hydroxyl group in hydroxylapatite using the $\mathrm{R}_{1}$ chain. Consequently, the bound bisphosphonates are ingested by osteoclasts during bone remodeling. By mimicking the structure of pyrophosphate (see Figs 2A and B), bisphosphonate competitively inhibits activation of essential enzymes that utilize pyrophosphate which leads to the death of the osteoclasts (Fig. 3). This leads to an overall decrease in the breakdown of bone; bisphosphonates are thus used to slow down bone loss. ${ }^{6}$

Bisphosphonates can either be taken orally or intravenously (IV). The IV route allows for intake of much larger doses of BP in less time, making IV bisphosphonates more potent than oral BPs (Fig. 4). ${ }^{6}$
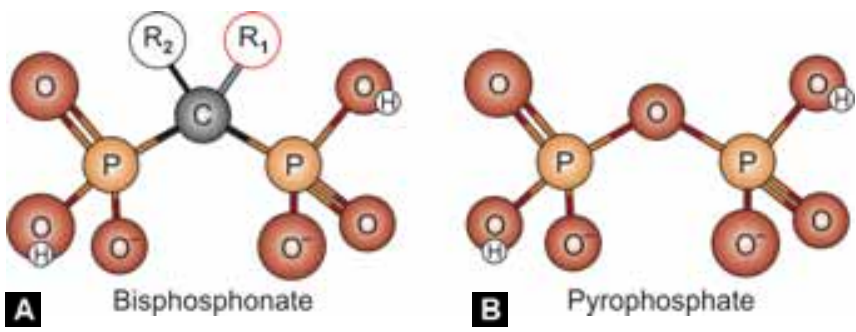

Figs $2 \mathbf{A}$ and $\mathbf{B}$ : The basic structure of bisphosphonate $(A)$ is very similar to the structure of pyrophosphate (B)

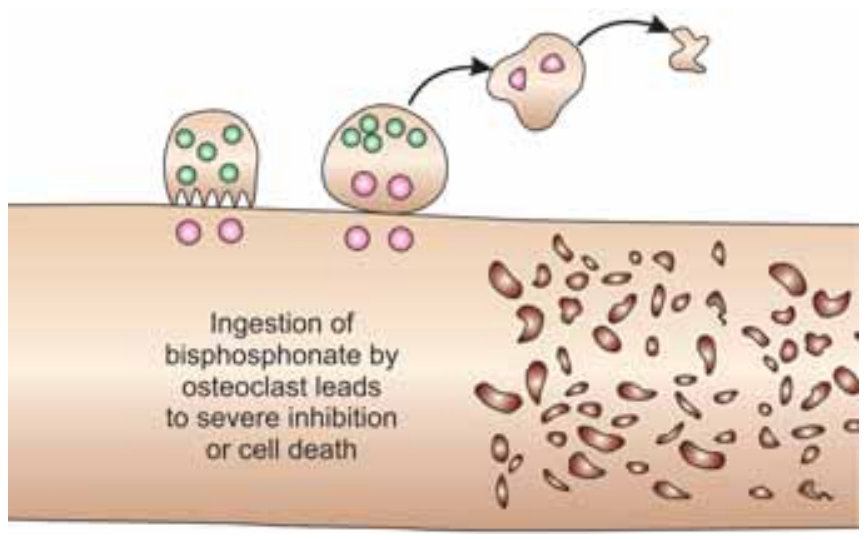

Fig. 3: Osteoclasts ingest bisphosphonates that are bound to bone and initiate apoptosis or cell death ${ }^{6}$

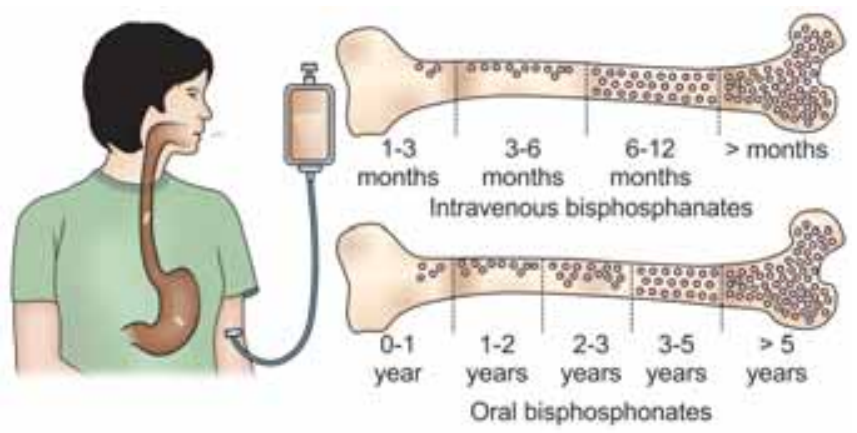

Fig. 4: Intravenous bisphosphonates accumulate in the bone in one year in the same amount that takes oral bisphosphonates to accumulate in 5 years. So, IVBPs are much more potent than oral BPs, acting faster and causing more harm ${ }^{6}$

\section{BP-Related Osteonecrosis of the Jaws}

Bisphosphonates have been used for half a century and only in the last decade have severe side-effects surfaced. Many patients who have undergone oral bisphosphonate treatment for several years, or several times intravenously, exhibited severe cases of irreversible osteonecrosis of the jaws (bisphosphonate-related osteonecrosis of the jaws, or BRONJ). ${ }^{6}$

The American Association of Oral and Maxillofacial Surgeons set a definition for BRONJ in their 2007 position paper. $^{8}$ According to AAOMS, patients are considered to have BRONJ if all of the following are present:

1. Current or previous bisphosphonate treatment.

2. More than 8 weeks of necrotic bone exposure in the maxillofacial region.

3. No history of radiation therapy to the jaws.

The updated definition will be later touched upon.

\section{The Staging of BRONJ}

A clear-cut list of stages for BRONJ has been the subject of debate among oral surgeons and researchers. Because certain cases of BRONJ have differed greatly from each other, not all cases can be applied to the system that the AAOMS arrived at. The main problem with the stages (Table 1 ) is the ambiguity of stage 0 , the stage of alarm, as it lacks one of the main aspects of BRONJ as per the definition, necrotic or exposed bone. As a result, the AAOMS definition was updated in 2009 (Table 2). This amendment includes stage 0 in the definition of BRONJ, solving the previous inconsistency. ${ }^{9}$ The symptoms of BRONJ that surface in stages 2 and 3 are summarized in Table 3.

\section{Why does BRONJ only Appear in the Jaws?}

It is important to assess the reasons why BRONJ is so unique to the jaws, and why BP patients do not experience osteonecrosis elsewhere in the body. First of all, BP uptake into local bone is in direct proportion to the local rate of bone turnover, and alveolar ridges have higher turnover than anywhere else in the body, so they accumulate more BPs in less time. ${ }^{6}$ Additionally, BP is toxic to epithelial tissues at a 


\begin{tabular}{|c|c|}
\hline & Table 1: Staging of BRONJ ${ }^{10}$ \\
\hline - Stage 0: & $\begin{array}{l}\text { No apparent necrotic/exposed bone } \\
\text { Hypoesthesia or anesthesia of lower lip } \\
\text { (Vincent's symptom) } \\
\text { Intraoral fistula } \\
\text { Deep periodontal pocket } \\
\text { Small osteolytic lesions on radiograph }\end{array}$ \\
\hline - Stage 1: & $\begin{array}{l}\text { Necrotic/exposed bone } \\
\text { Asymptomatic } \\
\text { No infection }\end{array}$ \\
\hline - Stage 2: & $\begin{array}{l}\text { Necrotic/exposed bone } \\
\text { Infection (pain, erythema) } \\
\text { With or without purulent discharge }\end{array}$ \\
\hline - Stage 3: & $\begin{array}{l}\text { Necrotic/exposed bone } \\
\text { Infection (pain, erythema) } \\
\text { With or without purulent discharge } \\
\text { Extending necrotic/exposed bone } \\
\text { Pathologic fractures } \\
\text { Extraoral fistula } \\
\text { Oral antral/oral nasal communication } \\
\text { Extending osteolysis }\end{array}$ \\
\hline
\end{tabular}

Table 2: Amendment to the definition of BRONJ9

All of the following must be present:

1. Current or previous bisphosphonate treatment

2. No history of radiation therapy to the jaws

3. More than 8 weeks of necrotic bone exposure in the maxillofacial region or no bone exposure with the following:

- Internal and/or external dental fistula

- Tingling sensation-neurological (Vincent's symptom)

- Deep local periodontal pocket

- Long-standing unhealed extraction

- Mixture of palely radiolucent and radiopaque areas or sequestration seen on conventional radiography

Table 3: Signs and symptoms associated with BRONJ ${ }^{10}$

- Pain

- Swelling

- Paresthesia

- Suppuration

- Soft tissue ulceration

- Intraoral fistula

- Extraoral fistula

- Loosening of teeth

- Radiographic lesions: Radiolucent, radiopaque or mixed

concentration of $1 \mathrm{nmol} / \mathrm{ml}$, but in alveolar bone it reaches 100 times this level due to high bone turnover. This causes the death of epithelial tissue, exposing the bone. ${ }^{12}$ Furthermore, tooth extraction or other dental trauma will result in BP release from bone that will inhibit the proliferation of adjacent epithelial cells. It follows that this leads to secondary bone infection in the presence of bacteria from the oral cavity. There are about 800 types of bacteria reaching 11 to 12 trillion in total found in the oral cavity. ${ }^{10}$ With all these factors in play, bone lesions of this kind are not found elsewhere in the human body, and only the

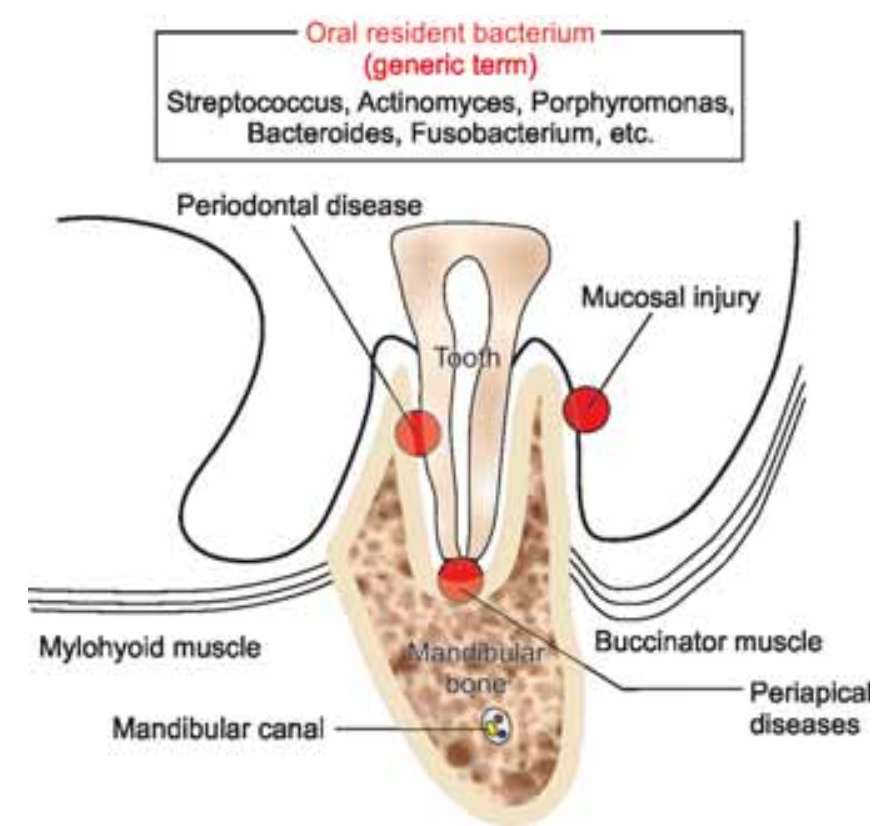

Fig. 5: Anatomy of the jaw. The unique emergence of teeth from bone into the oral cavity creates an exposure of the bone to possible infection and penetration of bacteria, unlike anywhere else in the body ${ }^{10}$

\begin{tabular}{|c|c|c|}
\hline \multicolumn{2}{|c|}{ Category/Subcategory } & Risk factors \\
\hline \multirow{2}{*}{ Drug-related } & Duration of use & Risk increases with time \\
\hline & Potency of drug & zoledronate $>$ Pamidronate $>$ Ora \\
\hline \multirow{9}{*}{ Local } & \multirow{5}{*}{$\begin{array}{c}\text { Invasive } \\
\text { Dental } \\
\text { Procedure }\end{array}$} & \begin{tabular}{|c|} 
Tooth extractions \\
\end{tabular} \\
\hline & & Dental implant placement \\
\hline & & Periapical surgery \\
\hline & & Osseous periodontal surgery \\
\hline & & Endodontic treatment \\
\hline & \multirow{2}{*}{ Mandible } & Mylohyoid ridge \\
\hline & & Lingual tori \\
\hline & Maxilla & Palapal tori \\
\hline & $\begin{array}{l}\text { Concomitant } \\
\text { Oral disease }\end{array}$ & $\begin{array}{l}\text { Inflammatory oral diseases, } \\
\text { dental and periodontal abscesses }\end{array}$ \\
\hline \multirow{4}{*}{\multicolumn{2}{|c|}{$\begin{array}{l}\text { Demographic and } \\
\text { systemic }\end{array}$}} & Age and sex \\
\hline & & Cancer \\
\hline & & Osteoperosis and Osteopenia \\
\hline & & Genetic MMP-2, P450 CYP2C8 \\
\hline \multirow{7}{*}{\multicolumn{2}{|c|}{ Other }} & Steroid therapy \\
\hline & & Diabetes \\
\hline & & Obesity \\
\hline & & Smoking \\
\hline & & Alcohol \\
\hline & & Poor oral hygiene \\
\hline & & Chemotherapeutic drugs \\
\hline
\end{tabular}

Fig. 6: Risk factors of developing BRONJ. Risk of developing BRONJ increases. The longer the period of treatment is and the more effective the BP molecule is. IV treatment is much more potent than oral. Invasive dental alveolar surgery increases risk by more than 7 times. As for regions where the gum is thin, these become predilection sites for BRONJ. Elderly women are considered to have the highest risk for developing BRONJ. Cancer patients are also at high risk. Matrix metalloproteinase-2 (MMP-2) and polymorphisms of cytochrome P450 have been suggested as genetic risk factors. Osteoporosis, osteopenia, steroid therapy, diabetes, obesity, smoking, alcohol, poor oral hygiene and chemotherapeutic drugs all increase the risk of developing BRONJ ${ }^{10}$

anatomy of the jaw (Fig. 5) allows the possibility of severe osteonecrosis due to BP uptake (Fig. 6). 

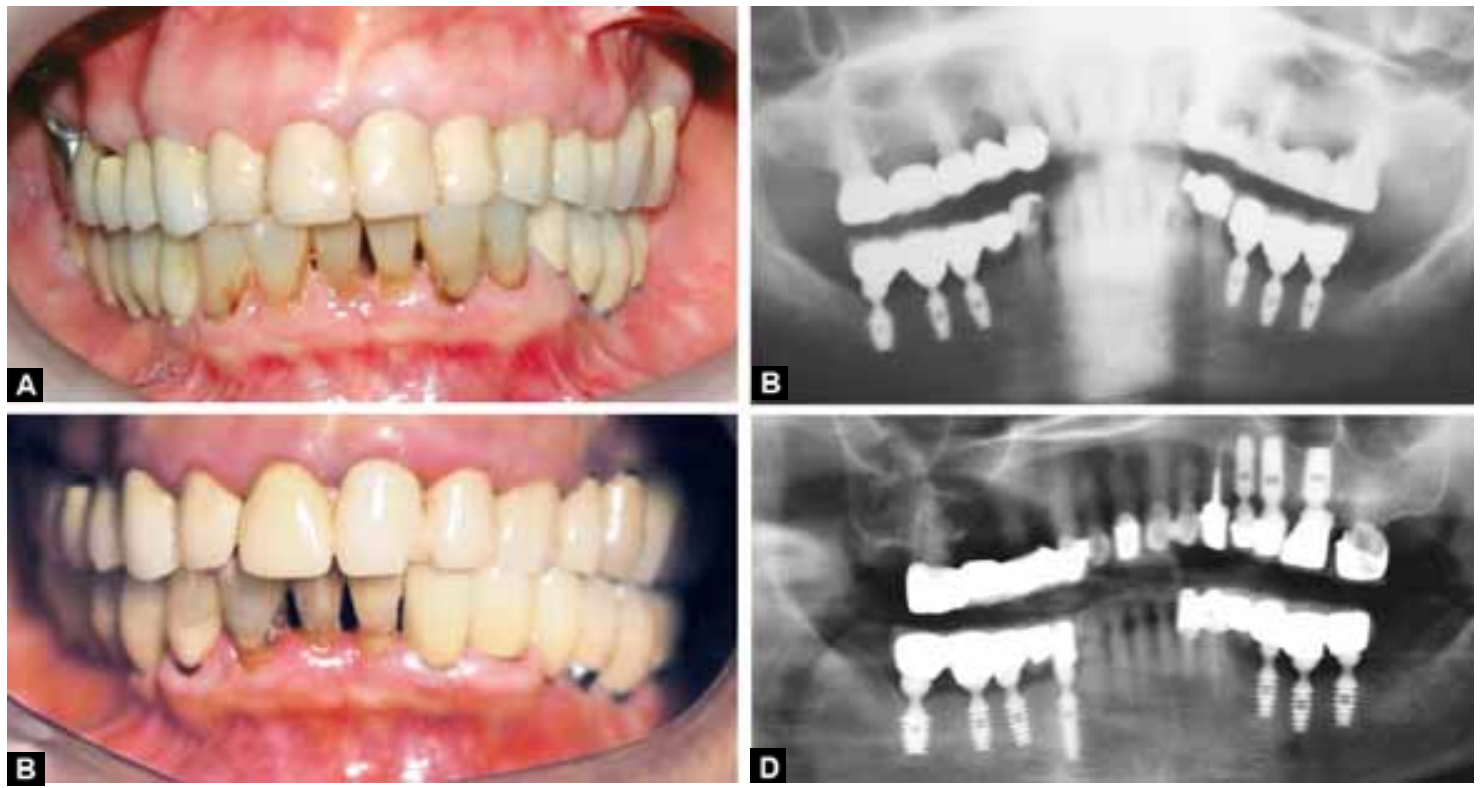

Figs 7A to D: Clinical (A) and radiographic (B) views directly after implant restorations in 1997 and later in 2007 (C and D)

\section{CASE STUDY}

Our BRONJ patient is a 77-year-old female with rheumatoid arthritis. She was treated for carcinoma of the larynx in 2004. She was previously a smoker but currently displays excellent oral hygiene. In the year 1997, we treated her by placing and restoring 6 implants to replace missing mandibular posterior teeth on both sides. Between 1997 and 2007 we provided her with three other implants to replace maxillary left 1st and 2nd premolars and 1st molar (Figs 7A to D). We also replaced her lower right 1st premolar in late 2007, early 2008.

The first complication was during the extraction of the lower left 1st premolar, which our endodontist deemed unrestorable (Fig. 8). A root canal treatment was applied to the lower left canine. The root canal was suspected after the patient presented with vague pain in that general area. As it turned out, the pain was actually caused by the extraction site, which had not healed properly yet. Because the patient complained of a feeling of heaviness and altered sensation, we restored the site with a three-unit fixed restoration rather than an implant.

The lower 2 central incisors and the right lateral incisor were extracted following perioperative complications (Fig. 9). Two implants were immediately placed and restored with the right central incisor as a pontic.

The patient presented with pain and granulation tissue under the pontic of the extracted premolar, which had not healed properly. A flap was raised and the implant at the right central incisor with granulation tissue at premolar was removed (Figs 10A to D). A temporary acrylic bridge prepared in the laboratory was placed to observe the site for a long period. Several months later, pain and purulence recurred. The removed tissue was sent for histopathology and showed osteomylitis (Fig. 11).
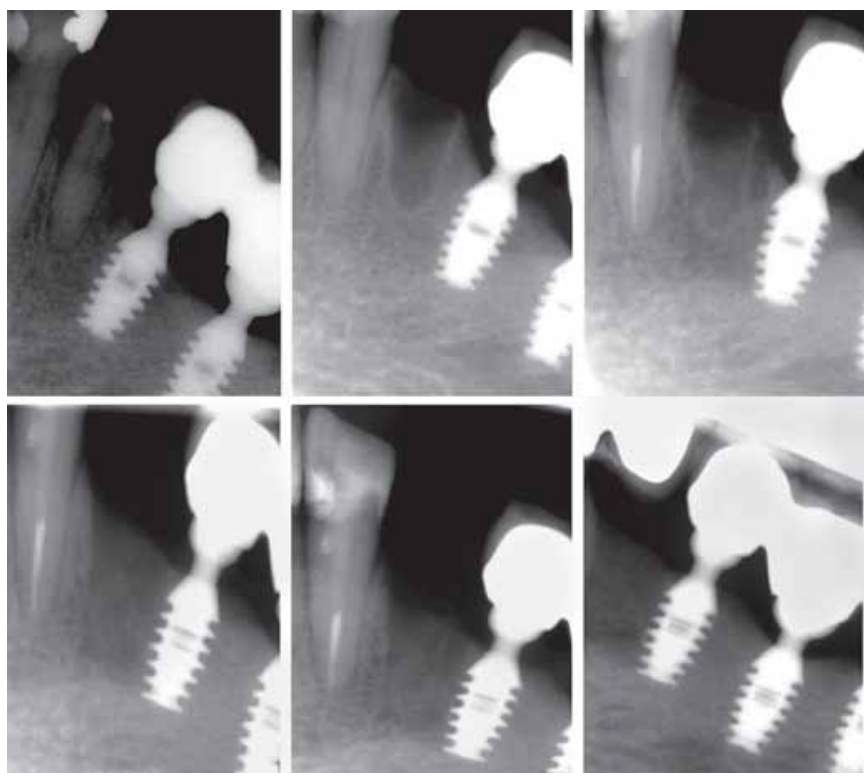

Fig. 8: Serial periapical radiographs showing failing tooth at lower left 1st premolar before extraction (top left) and several other ones after extraction. This shows improper bone healing over time and the unnecessary root canal therapy for the canine due to misleading pain in the area

The uneventful healing of the extraction site with the unhealed implant site and the misleading sensation and pain that instigated the root canal treatment of neighboring teeth with the purulence and steroid treatments for long periods in a female older than 60 years of age, are all predisposing factors of BRONJ. Since the patient had been treated 5 years earlier for carcinoma of the larynx via radiotherapy of the neck region, we suspected osteoradionecrosis. The treating physician assured us that the mandible had not been included in the field and that it had been properly protected.

The patient had actually been on a regimen of oral BP for 10 years and had only shifted to IV 2 years earlier, as 


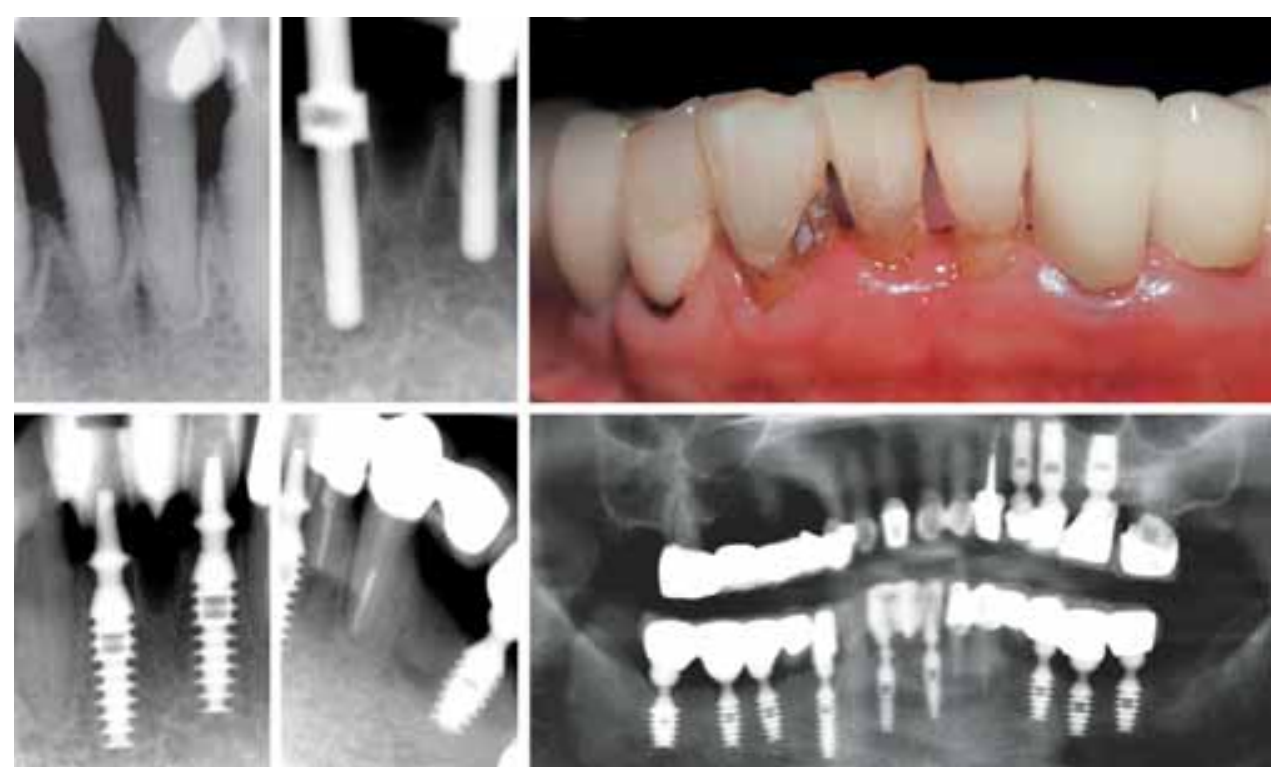

Fig. 9: Clinical (top right) and radiographic views showing the restoration of missing left first premolar with a fixed restoration and a cantilevered pontic; also showing the failing lower anteriors that were extracted and replaced with 2 implants with immediate fixed restoration
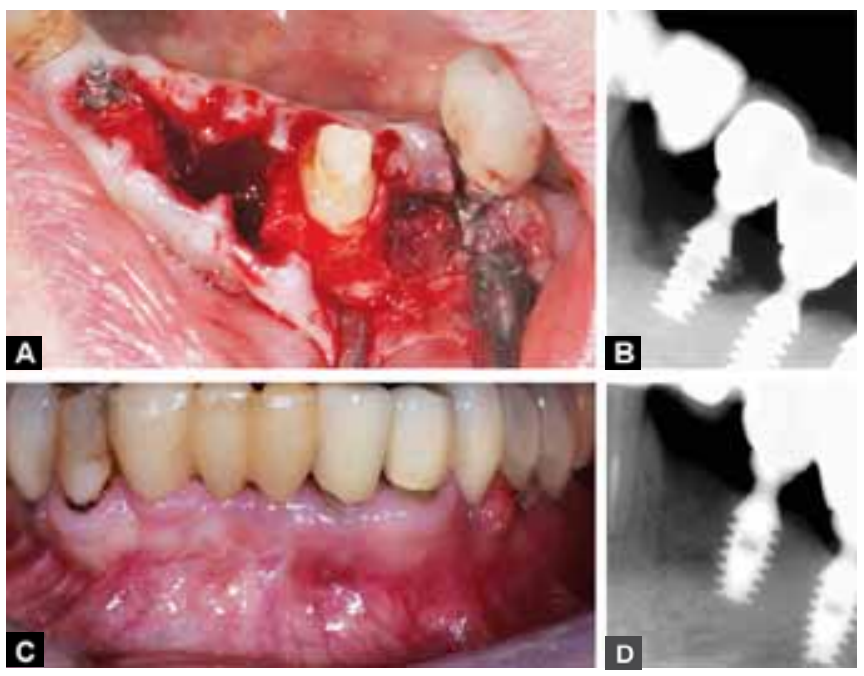

Figs $10 A$ to $D$ : Granulation tissue revealed clinically $(A)$ and sequestra shown radiographically $(B$ and $D)$ despite the lack of bone exposure $(C)$
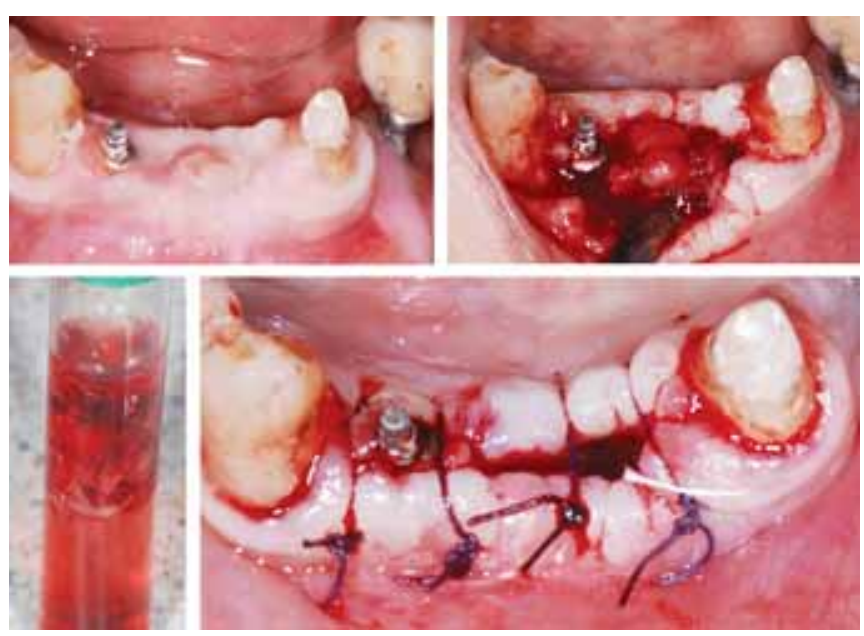

Fig. 11: Recurrence of inflammation with purulence that was curetted to be sent for histology (lower left). The results of the tests revealed chronic osteomyelitis she explained to us later, but it had not occurred to her to inform us at the time because she did not think this issue could possibly concern her dentist. She even thought that BP had strengthened her bones. Furthermore, her physician never asked her to get her teeth checked before he put her on the BP regimen, especially the IV one.

We on the other hand, assumed she was fine, as we had placed several implants for her over the past decade or more, we thus deemed it unnecessary to update her file. This is not to say that we were not responsible. Still, the responsibility is all of ours: Patient, physician and dentist. Now, two debridements later, the big alarm came with a panoramic X-ray (Fig. 12) that showed the moth-eaten appearance of osteomyelitis deep in the mental area. A CT scan showed the sequestra in bone (Fig. 13). The patient was hospitalized and placed under general anesthesia after which aggressive debridement of the site was done with the removal of the lower left canine and 2 implants at the lower right lateral incisor and the lower left 2nd premolar (Fig. 14).

Before hospital surgery we had to prepare the temporary restoration she would need after surgery. As the edentulous space would be between the lower right canine to the left first molar (7 teeth missing), a temporary bridge was fabricated whose abutments were lower right canine and first premolar on one side, and the first and second left molar on the other side. This was done after cutting and removing the crowns on 3 implant-abutments and preparing one natural tooth (the lower right canine) (Fig. 15).

Two weeks after surgery, sutures were removed where it was clear that at 2 sites, bone was exposed and soft tissues had not healed properly (Figs 16A and B). Even 3 months following surgery, the bone was still exposed (Fig. 17). Still, the patient presented with no pain or any sign of inflammation. As such, the decision to restore the site with 


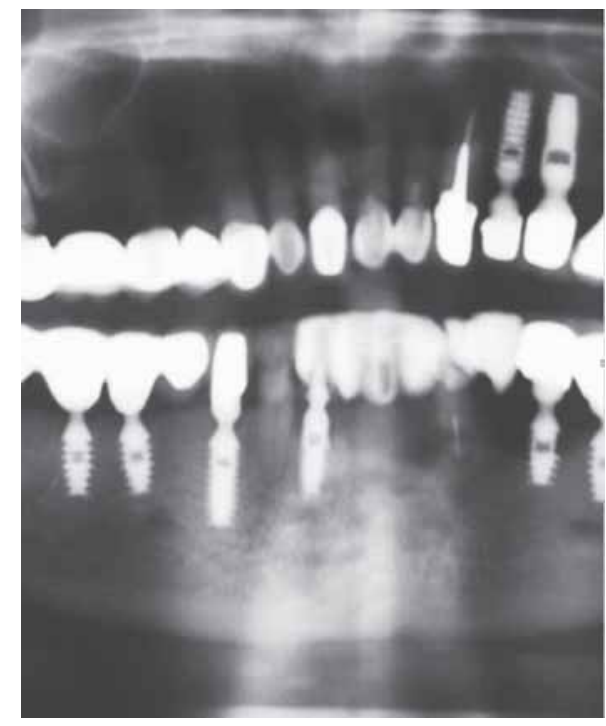

Fig. 12: This is the radiograph that called for aggressive surgery at the hospital under general anesthesia to eliminate all infected bone in the mental area. The moth-eaten appearance of the jaw bone can be observed where there is a mixture of radiolucent and radiopaque areas on the radiograph

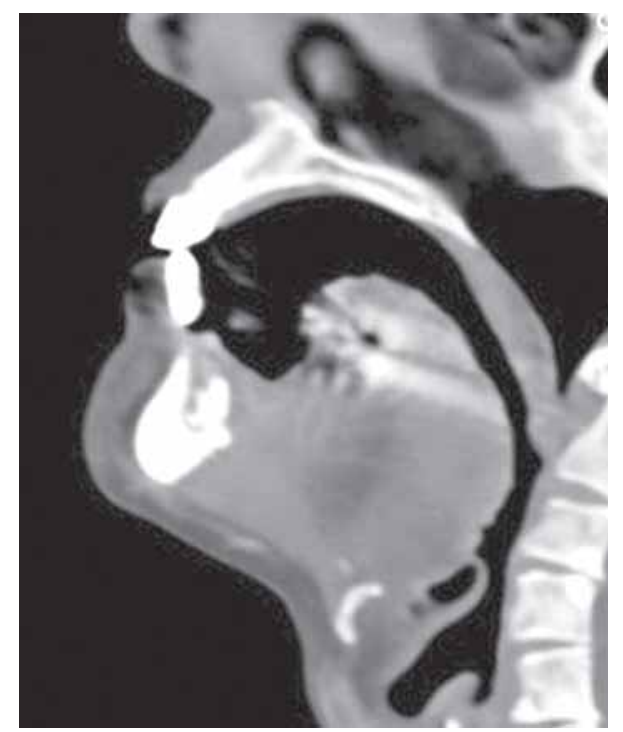

Fig. 13: A CT scan of the patient's mandible with IV contrast shows a bony defect with a sequestrum at the lingual aspect of the symphysis area
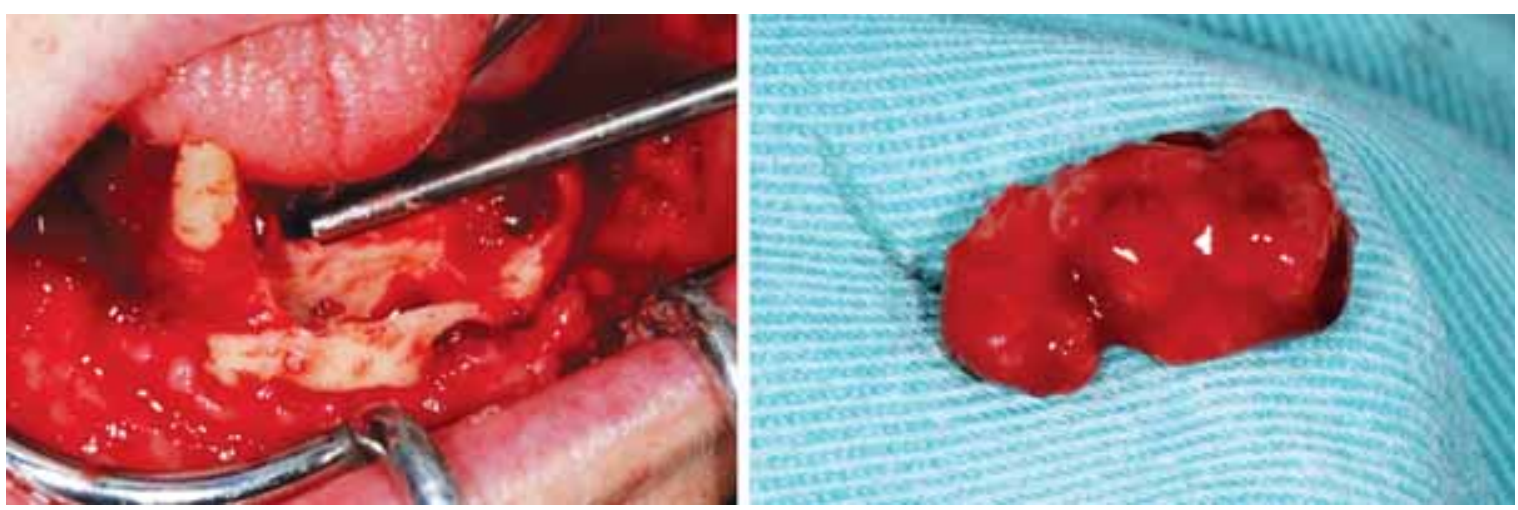

Fig. 14: The surgical site after debridement. The sequestra and the granulation tissues were removed and sent for histopathological assessment
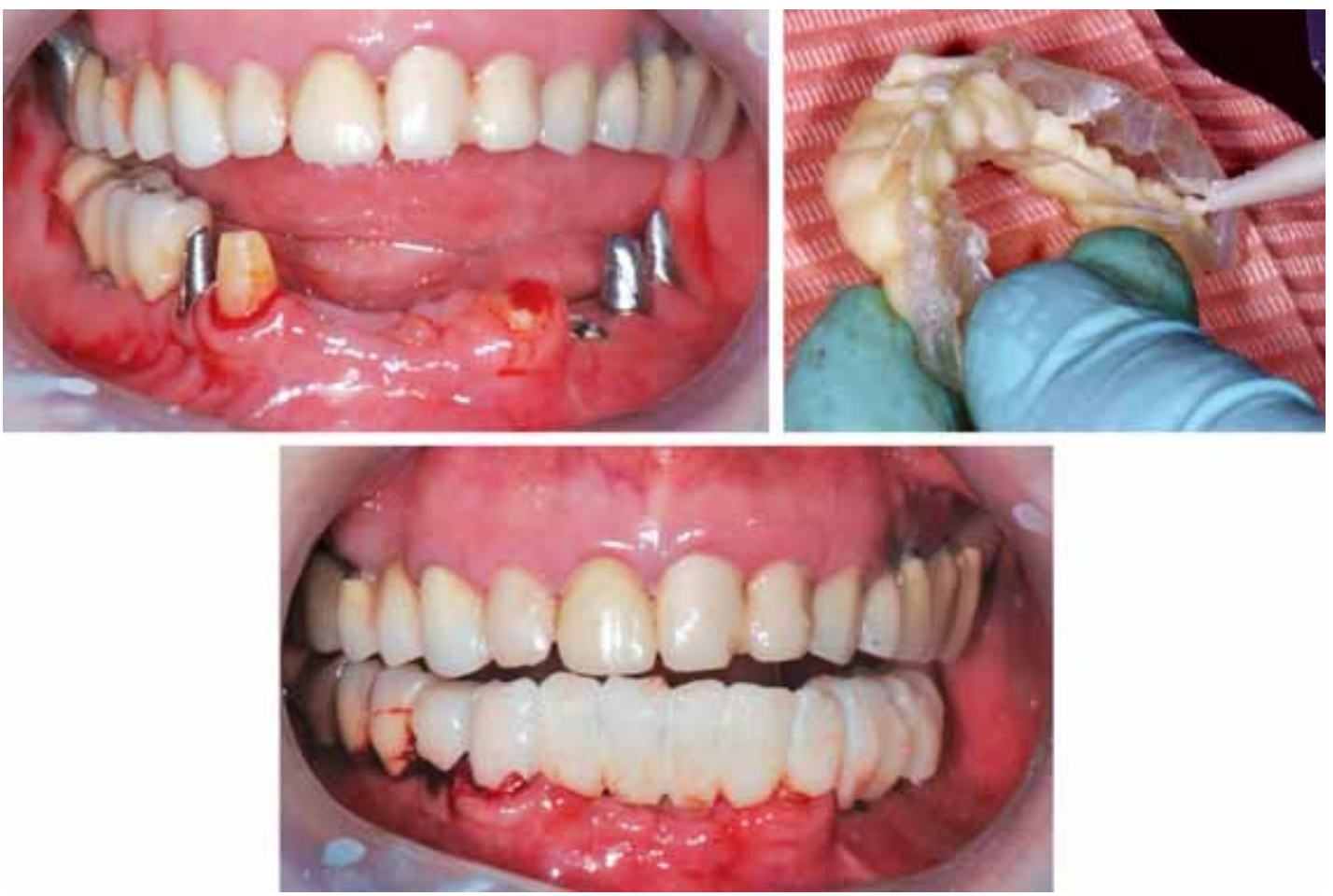

Fig. 15: The fabrication of the temporary restoration right before hospital surgery 

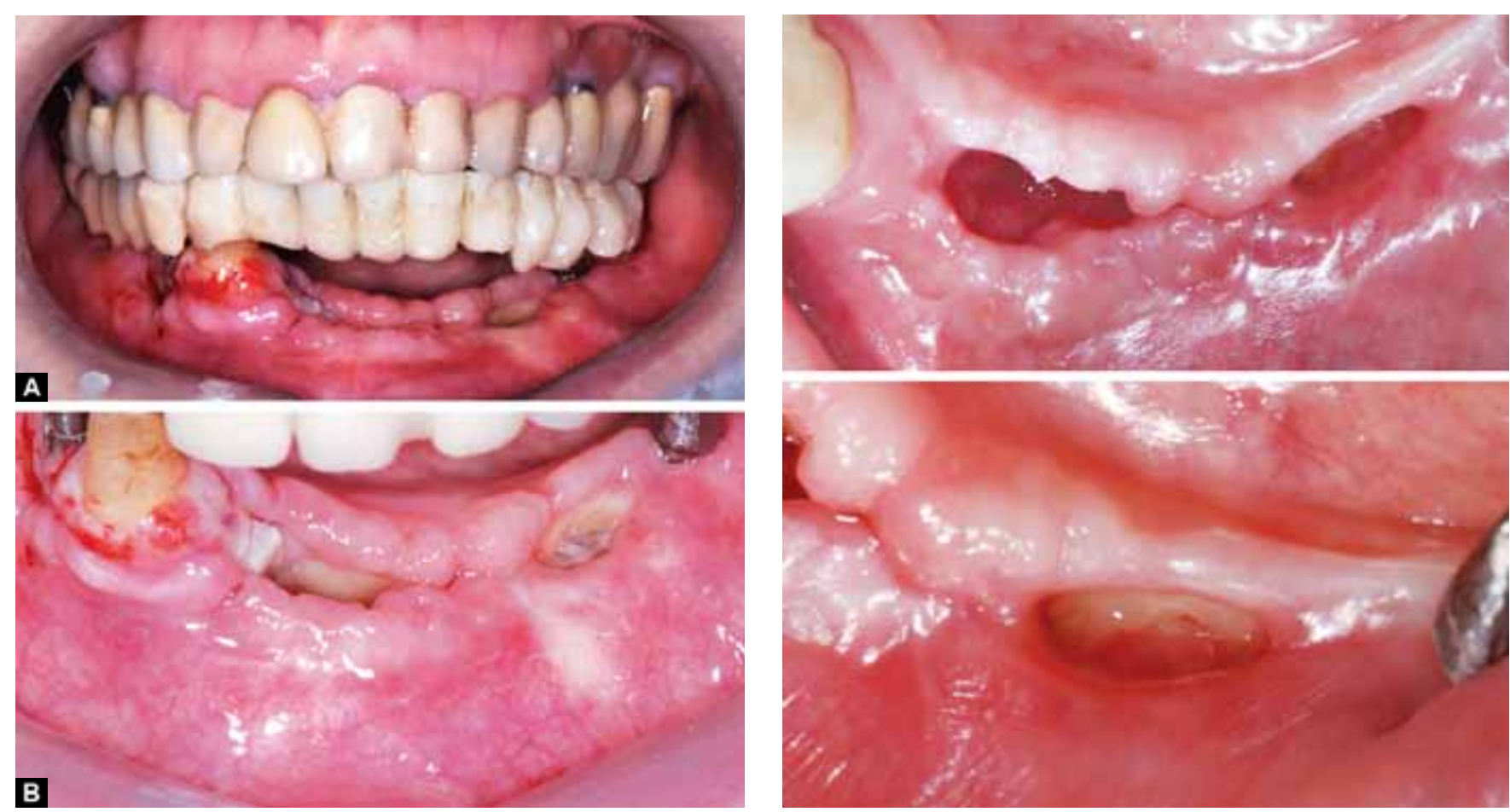

Figs 16A and B: Surgical site 2 weeks postoperative shows the amount of vertical bone loss $(A)$ and the two sites of bone exposure after suture removal (B)

Fig. 17: Surgical site 3 months postoperative, bone is still exposed but without any symptoms or signs of inflammation. This falls under stage 1 BRONJ according to AAOMS
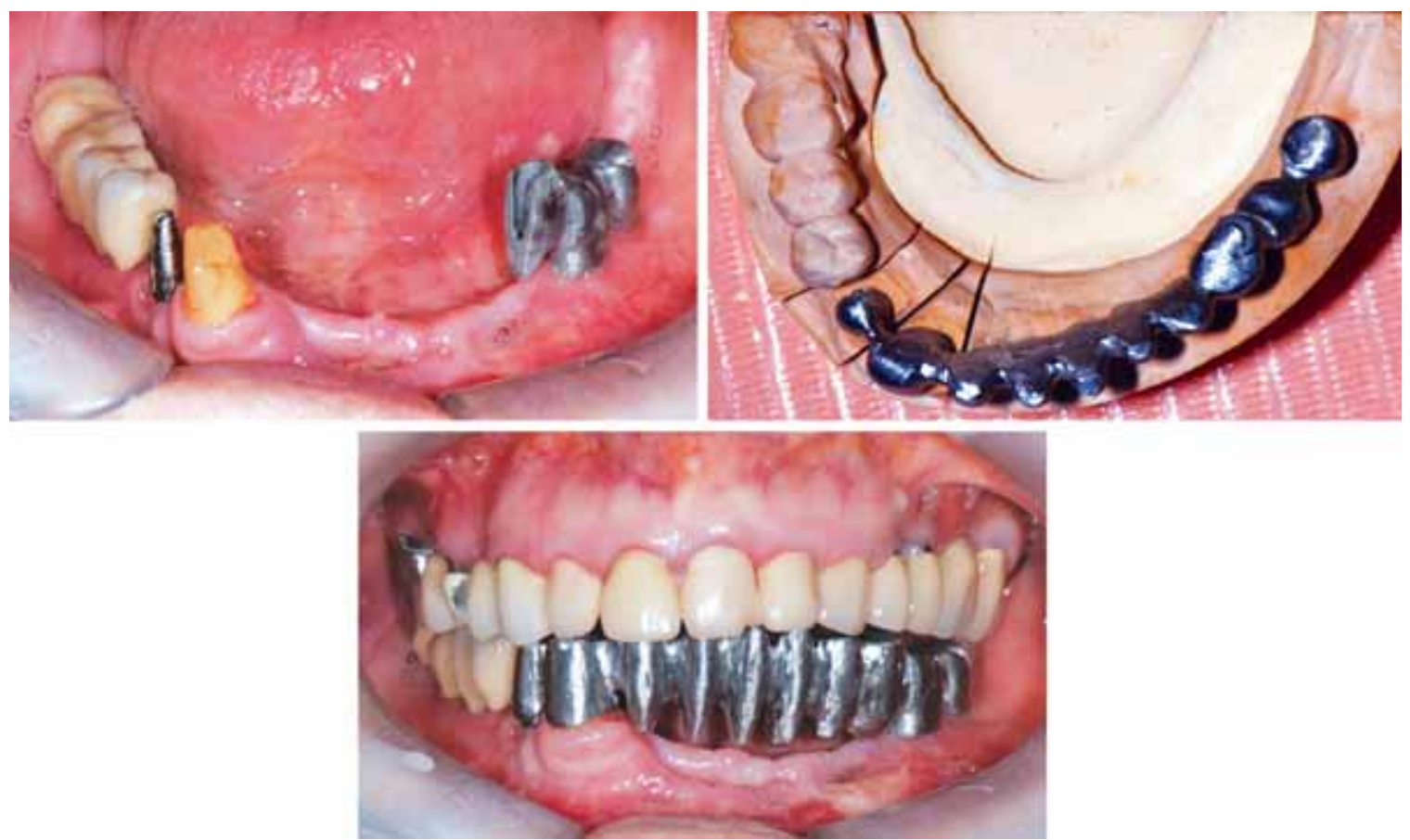

Fig. 18: Try-in stage of the metallic infrastructure of the temporary ceramometallic bridge

a temporary ceramometallic bridge was taken. Since we had to check the exposed bone frequently, the bridge we created consisted of two pieces connected at the first molar site with a semiprecision attachment and cemented using temporary cement (Figs 18 and 19). Even though the inciso-gingival height of the crowns on pontics was excessive (compared to neighboring teeth), this did not have a visible effect as the lower lip covered the gingival part of these teeth (see Fig. 19). The posterior occlusion on the implants bilaterally was maintained leaving anterior teeth and left premolars off occlusion (Fig. 20). Proper oral hygiene instructions were given to the patient, including the use of super floss (Fig. 21).

The patient was instructed to come every 4 to 6 weeks for clinical check-ups. During the 18-month follow-up period, the size of the exposed bone continued to decrease 

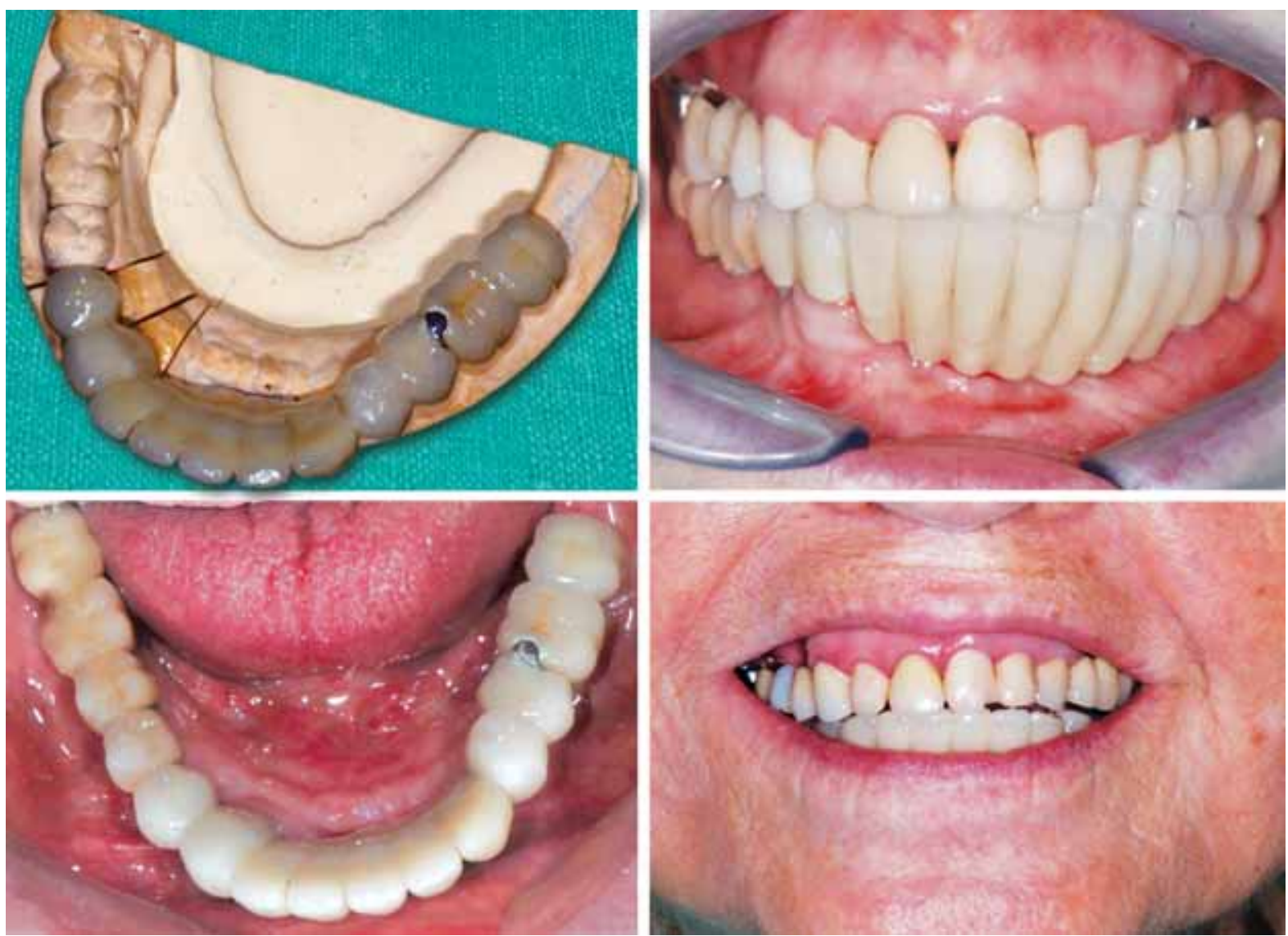

Fig. 19: Delivery of the temporary ceramic bridge (top left).

Lower lip (lower right) covering the gingival part of the extralong anterior teeth (top right)

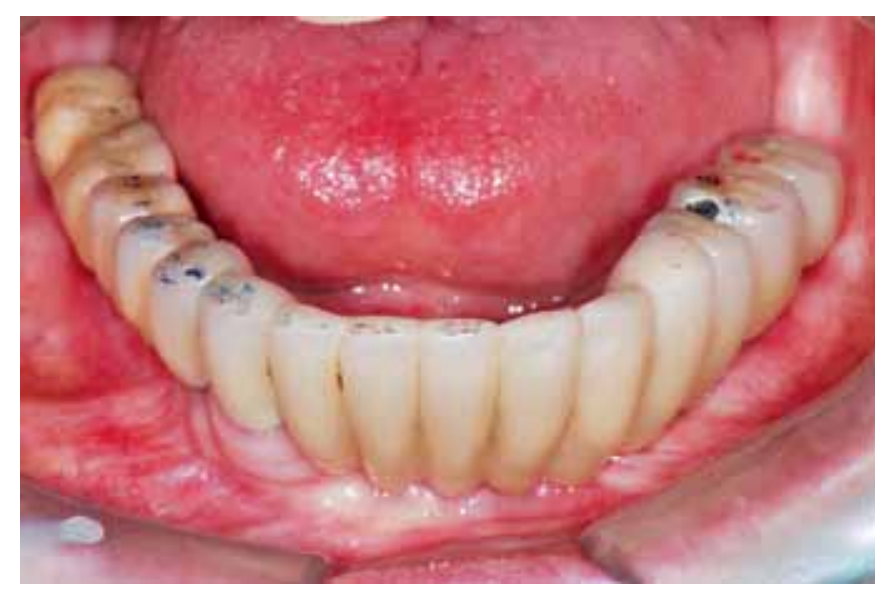

Fig. 20: Occlusion is only maintained on the posteriors where we have implants

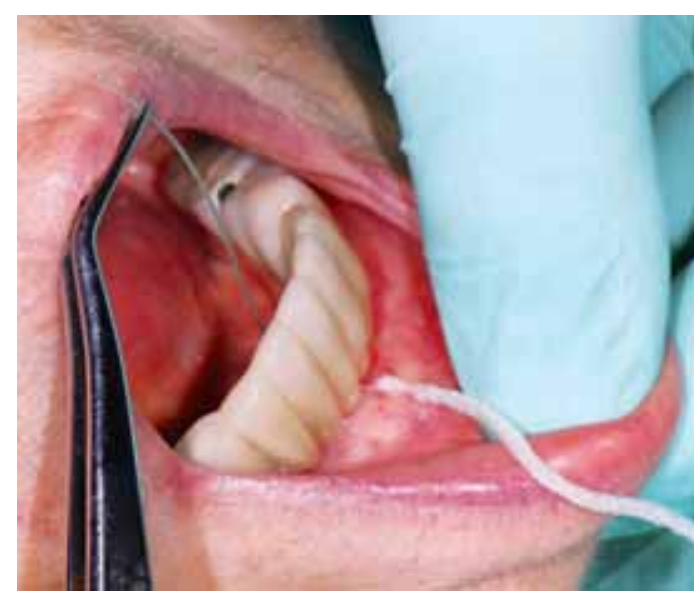

Fig. 21: Proper oral hygiene instructions including the use of super floss with no signs of inflammation (Fig. 23) and the panoramic radiographs showed progressive bone healing (Figs 22 and 24). The patient's physician instructed her to stop taking BPs since it had been given as a prophylactic treatment for a mild case of osteoporosis. He instructed her to manage her osteoporosis with calcium and vitamin D instead.

A laboratory risk assessment for patients taking BP is testing the C-terminal crosslinking telopeptide. Our patient has undergone this test twice and the results were 327 $\mathrm{pg} / \mathrm{ml}$ and $308 \mathrm{pg} / \mathrm{ml}$, this means that there is no risk of BRONJ after surgical intervention according to Marx, whose threshold value for no risk is $300 \mathrm{pg} / \mathrm{ml} .^{6}$

At this point of our treatment, our temporary ceramometallic bridge is functioning well in the patient's mouth. However, if surgical intervention for implant placement is to be done later, it can be done easily according to the test results shown earlier. 


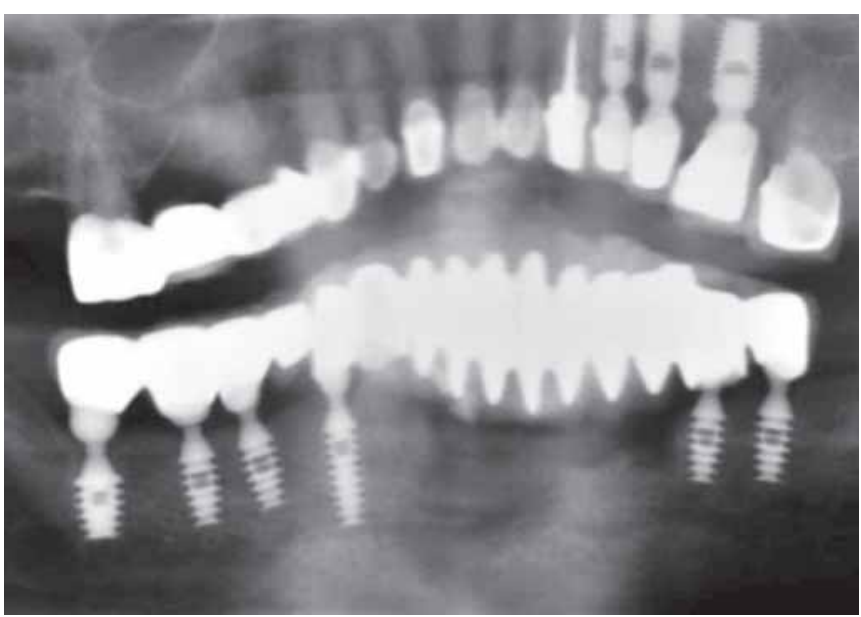

Fig. 22: The panoramic radiograph immediately after bridge fabrication shows the extent of bony defect 3 months after surgery
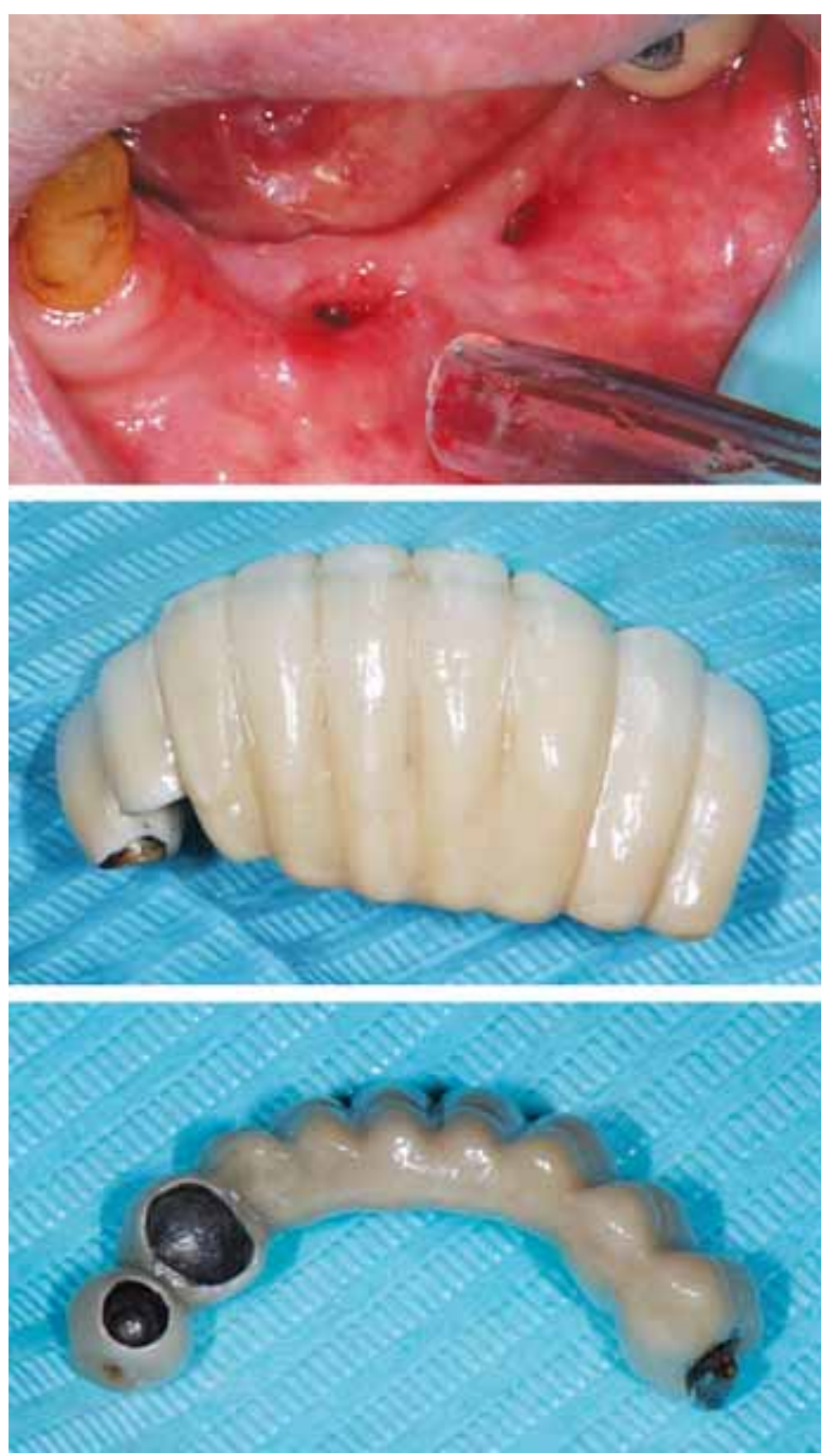

Fig. 23: A clinical check-up session 14 months after surgery shows that the tissues still show 2 small openings at the site of surgery but with no signs or symptoms of inflammation (top)

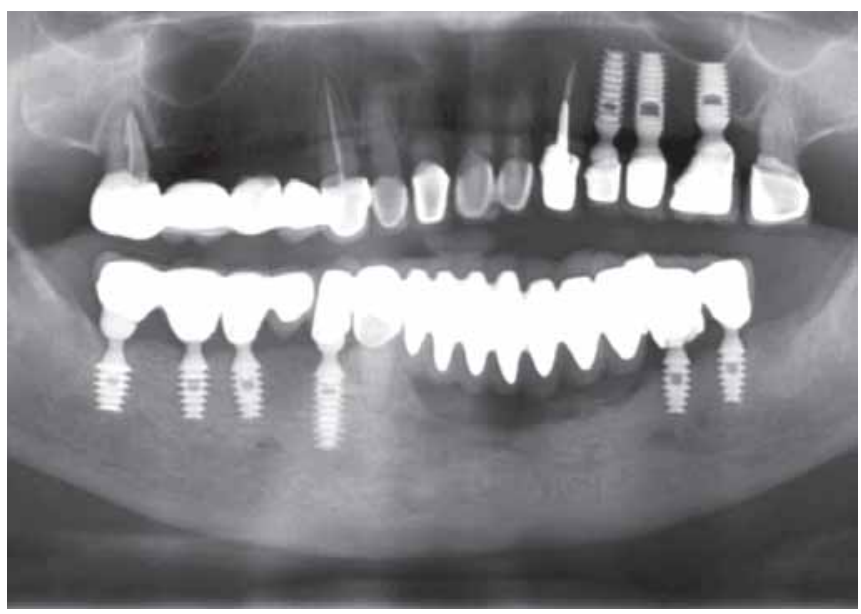

Fig. 24: Panoramic view on a radiograph taken 22 months after surgery shows good bone fill compared to the radiograph taken 3 months postoperative

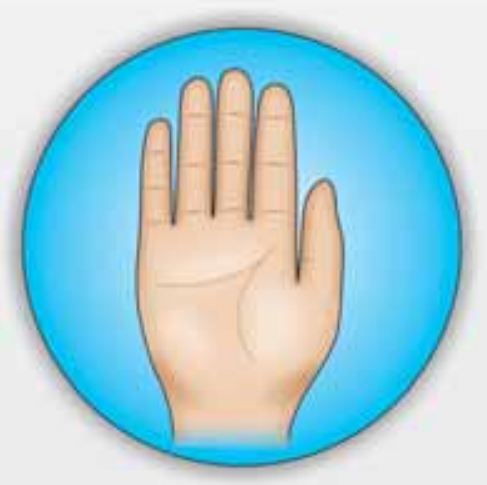

A dental examination with appropriate preventive dentistry should be considered before starting treatment with pamidronate. This is especially important if you:

- Have poor dental health;

- Have cancer:

- Are receiving chemotherapy; or

- Are taking corticosteroids.

Fig. 25: In 2004, the FDA required the placement of an adverse reaction statement on all intravenous bisphosphonates as a warning of their potential dental risks ${ }^{6}$

\section{DISCUSSION}

According to AAOMS, patients are considered to have BRONJ, if the patient is on or had undergone bisphosphonate treatment; the patient has necrotic bone exposure in the maxillofacial region for more than 8 weeks; and if there was no history of radiation therapy to the jaws. Our patient has all three of these criteria and this lead us to diagnose her with BRONJ. Staging criteria for BRONJ has been put forward by AAOMS and it is based on the cancer tumor staging model. Our patient does not clearly fall under any single category within the current assigned stages. In the beginning she had pain, infection and purulence but there was no exposure of the bone. No exposed bone would signify stage 0 according to the AAOMS amendment. As the case progressed we saw necrosis and sequestra, but no bone exposure. The patient was at this point extremely 
symptomatic, but therein lies the dilemma of the AAOMS staging of BRONJ. Stage 2 requires exposed bone, but our patient experienced all the stage 2 requirements except bone exposure. After surgery and removal of sequestra and necrotic bone, the patient was in true stage 2 exposed bone, but asymptomatic.

Our main concern is the lack of patient education regarding BRONJ as a possible side effect of oral and IV bisphosphonates (Fig. 25). There was also a lack of communication between the patient's physician and her dentist, and this led to an extreme delay of proper diagnosis and the deterioration of the patient's condition before measures of prevention were taken.

\section{RECOMMENDATIONS}

Our experience dealing with our BRONJ patient has given us new insight that may help to prevent or decrease the occurrence of BRONJ as a result of dental procedures. Our recommendations are as follows:

1. Update patient's files every 6 months at check-up time and clearing with the patient's signature.

2. Include BP use as a separate entity in the patient's file.

3. Communicate with physicians and educate the patients about BRONJ and BPs.

4. Neurosensory disturbance (Vincent's symptom) is a possible early indicator of BRONJ.

5. Missed diagnosed root canal therapy is another possible early sign of BRONJ.

6. Sclerotic lamina dura and widened periodontal ligament space are important indicators of BRONJ.

7. Pain of unknown origin could mean BRONJ.

8. Beware of misdiagnosed osteolytic or osteosclerotic bone area on radiographs.

9. Add risk of BRONJ to your consent forms for patients undergoing BP therapy.

10. Open your eyes wide for future literature and position papers related to BRONJ diagnosis and treatments.

\section{REFERENCES}

1. Fleisch H. Development of bisphosphonates. Breast Cancer Res 2002;4(1):30-34.
2. Marx RE. Pamidronate (Aredia) and zoledronate (Zometa) induced avascular necrosis of the jaws: A growing epidemic. J Oral Maxillofac Surg 2003;61:1115-17.

3. Hellstein JW, Marek CL. Bisphosphonate osteochemonecrosis (bis-phossy jaw): Is this phossy jaw of the 21st century? J Oral Maxillofac Surg 2005;63:682-89.

4. Dearden WF. Fragilitas ossium amongst workers in Lucifer match factories. Brit Med L 1899;2:270

5. Dearden WF. The causation of phosphorus necrosis. Br Med J 1901;2:408.

6. Marx RE. Oral and intravenous bisphosphonate-induced osteonecrosis of the jaws: History, etiology, prevention, and treatment. Quintessence Publishing, Carol Stream, IL 2006.

7. Edwards BJ, Hellstein JW, Jacobsen PL, Kaltman S, Mariotti A, Migliorati CA. American Dental Association Council on Scientific Affairs Expert Panel on bisphosphonate-associated osteonecrosis of the Jaw. Updated recommendations for managing the care of patients receiving oral bisphosphonate therapy: An advisory statement from the American Dental Association Council on Scientific Affairs. J Am Dent Assoc 2008;139:1674-77.

8. Advisory Task Force on Bisphosphonate-Related Osteonecrosis of the Jaws. American Association of oral and maxillofacial surgeons position paper on bisphosphonate-related osteonecrosis of the jaws. J Oral Maxillofac Surg 2007;65:369-76.

9. Ruggiero SL, Dodson TB, Assael LA, Landesberg R, Marx RE, Mehrotra B. American Association of oral and maxillofacial surgeons position paper on bisphosphonate-related osteonecrosis of the jaws-2009 update. J Oral Maxillofac Surg 2009;67(5 Suppl):2-12.

10. Yoneda T, Hagino H, Sugimoto T, Ohta H, Takahashi S, Soen S, Taguchi A, Toyosawa S, Nagata T, Urade M. Bisphosphonaterelated osteonecrosis of the jaw: Position paper from the Allied Task Force Committee of Japanese Society for Bone and Mineral Research, Japan Osteoporosis Society, Japanese Society of Periodontology, Japanese Society for Oral and Maxillofacial Radiology, and Japanese Society of Oral and Maxillofacial Surgeons. J Bone Miner Metab 2010;28:365-83.

11. AADR Annual Meeting Washington DC. American Association for Dental Research 2010.

12. Reid IR, Bolland MJ, Grey AB. Is bisphosphonate-associated osteonecrosis of the jaw caused by soft tissue toxicity? Bone (NY) 2007;41:318-20. 